\title{
As Novas Cartas Portuguesas ou uma nova cartografia do feminino
}

\author{
Alda Maria Lentina \\ Universidade de Dalarna
}

Resumo: Se, em Novas Cartas Portuguesas “a mulher continua, metafisicamente, a ser sinónimo de 'carne' ou seja, 'um corpo sem alma', sendo, por isso, a antítese da razão inerente ao sexo masculino" (Simosas 2007), existe no entanto, por parte das autoras, uma vontade clara de problematizar e ultrapassar esta situação secular regressando a este corpo "that matters" (Butler 2005). A multiplicidade das vozes e experiências femininas presentes na obra, delineia um projecto político que impõe a "materialidade" do corpo feminino ao "Escrever o corpo, falar do desejo feminino, (...), como se (...) fosse necessário [as mulheres] cartografar[em]-se (...)" (Cunha 2012) para dar "corpo" à sua voz. Transformado em motor e território da escrita, o corpo feminino faz da escrita o corpus de um corpo "não monarquizado" (Cixous 2010), ligando o acto da escrita ao conceito de "escrita-mulher" (Didier 1981). Assim, o que está em jogo é a passagem de uma "feminilidade informe” (Butler 2005), cujo corpo foi “castrado e eufemizado" (Greer 1971), a um empoderamento, perturbante e transgressor. Este movimento questiona a visão de um eterno feminino imposto pela sociedade patriarcal e valorizado pelo regime salazarista. Ao falarem de um "corpo mutante" (Dorlin 2009), auto-erótico e ciente dos seus desejos, capaz de experimentar e exprimir uma verdadeira libertação do corpo feminino, as Novas Cartas Portuguesas fazem da mulher o sujeito de um "corpo não (...) adormecido" (Barreno/Horta/Costa 2010), cuja presença e expressão "histeriza[m] o espaço social" (Cixous 2010) provocando uma r-evolução.

Palavras-chave: desconstrução do Eterno Feminino, corpo feminino, sexo/sexualidade e erotismo

Abstract: If, in New Portuguese Letters, "women continue, metaphysically, to be synonymous with 'flesh', that is, 'a body without soul', being therefore the antithesis of the reason generally inherent to male sex" (Simosas 2007), there is however, on the part of the authors, a clear determination to problematize and overcome this 
secular situation returning to this body "that matters" (Butler 2005). The multiplicity of female voices and experiences present in the book defines a political project that imposes the "materiality" of the female body by "writing the body, speaking about female desire, (...), as if it was necessary to [Women] to map themselves ..." (Cunha 2012) to give "body" to their voice. Transformed, at the same time, into a motive and a territory of the writing itself, the female body forms the corpus of a "non-monarchical" body (Cixous 2010) relating the act of writing to the concept of "escrita-mulher" (Didier 1981). Therefore, what takes place in the work is the shift from a "shapeless femininity" (Butler 2005), whose body was "castrated and euphemised" (Greer 1971) to a disturbing and transgressive empowerment. This movement questions the specific vision of an eternal feminine imposed by patriarchal society and valued by Salazar's regime. By speaking of a "mutant body" (Dorlin), self-erotic and aware of it's one desires, capable of experiencing and expressing a true liberation of the female body, New Portuguese Letters turn woman as a subject of a "not (...) asleep Body" (Barreno/Horta/Costa 2010), whose presence and expression "hystericizes the social space" (Cixous 2010) taunting a r-evolution.

Keywords: deconstruction of the Eternal Feminine, female body, sex/ sexuality and eroticism

Quando, em 1949, Simone de Beauvoir publica Le Deuxième Sexe (Beauvoir 1976), o livro é acolhido por uma vaga de reacções conservadoras e machistas. Assim, figuras como Albert Camus, François Mauriac e outros, viam neste texto um "insulto ao macho latino" ou a obra de uma "pobre neurótica", acabando por declarar saberem "tudo do clitóris e da vagina da autora". ${ }^{1}$ Pouco mais de vinte depois, em Portugal, em Abril de 1972, as Três Marias publicam Novas Cartas Portuguesas (Barreno/Horta/Costa 2010) e a recepção é semelhante, sendo as autoras acusadas pelo regime salazarista de "imoralidade e de pornografia". Mudam-se os tempos, mas não as vontades. As duas obras, distantes e diferentes na sua forma, mas afinal muito próximas no conteúdo, são portadoras de uma transgressão suprema. Esta transgressão reside nas formas como as escritoras se apoderam dos "factos e dos mitos"2 ligados ao feminino, dando uma visão clara da "existência vivida" pelas mulheres, falando, em particular, da sua sexualidade e desmitificando o que sempre foi considerado pelos homens como o freudiano "continente negro". Com efeito, os dois 
livros provocam uma verdadeira onda de "choque" 3 nas sociedades em que foram publicados, porque ousam problematizar o corpo feminino, tradicional objecto do imaginário masculino. No que diz respeito a Novas Cartas Portuguesas e à sociedade portuguesa dos anos 70, abafada por um regime ditatorial, o acto de "reconhecer oficialmente e publicamente à mulher o direito à sexualidade conduziria ao aniquilamento de todo o edifício da ideologia corporativista, que fazia da família a célula base da sociedade e da mulher a dedicada e casta esposa" (Machado 1996: 734). Neste sentido, a obra das Três Marias é inovadora, porque utiliza a escrita para edificar um corpus no feminino, redefinindo os contornos da feminilidade, ${ }^{4}$ na sua substância e materialidade. A obra anuncia uma insurreição feminina, através de um re-centramento ou de um regresso à materialidade deste corpo "that matters". 5

\section{"Maria é a raiz"6}

A problematização da corporalidade feminina começa a emergir na obra com a questão do nome, assinalada por uma cadeia de nomes femininos. No seu prefácio, surgido inicialmente na edição da Moraes Editora, em 1980, e depois retomado na edição da Dom Quixote, de 2010, Maria de Lurdes Pintasilgo sublinha que:

[n]este "fresco" é Mariana a figura central, a trama principal de uma história inenarrada, são outras histórias, fugazmente captadas, que lhe dão relevo e significado. Como se o nome, intacto ou fragmentado (Maria, Ana, Maria-Ana, Ana Maria (...), recapitulasse a sua própria vida nas vidas de outras mulheres nascidas em outros momentos e lugares. (Barreno/Horta/Costa 2010: XXXIV)

Retomando o tema do "nome" associado a uma "história inenarrada", podemos igualmente ver na cadeia dos nomes uma tentativa de problematização da identidade feminina na sua tradicional ligação com um processo de desmaterialização corpórea. $\mathrm{Ou}$ seja, uma forma de "hiper-abstracção" apontada por J. Kristeva em "Stabat mater" (Kristeva 1986: 173). Assim, da leitura dos títulos de algumas composições de Novas Cartas Portuguesas, destaca-se uma impressão de acumulação de nomes femininos, muitos dos quais são derivados de Mariana (Alcoforado 1993), ${ }^{7}$ funcionando ou como citação 
reiterativa dos nomes, Maria e Ana (nomes típicos da onomástica feminina) ou, então, como símbolos de configurações femininas louvadas pelo salazarismo. É o caso, por exemplo, de Isabel, Fátima e Inês. Ora se, como nos é dito na obra, "Maria é a raiz" (Barreno/Horta/Costa 2010: 25), podemos descortinar nestas outras, Inês, Fátima e Isabel, ${ }^{8}$ a sua imagem duplicada. Com efeito, o nome Maria reenvia para o culto cristão a Maria (o marianismo), mais precisamente a um modelo feminino idealizado e desencarnado, que serviu de padrão para a "hierarquização do corpo ou do visível" (Vigarello 2004: 17) feminino na cultura ocidental. Esta ideia aponta para o facto de que a história da feminilidade só se reflecte nas imagens e figurações propostas/impostas pelo imaginário masculino, em constante alternância entre idealização e rebaixamento, o que a historiadora Michelle Perrot qualifica como "a abundância dos discursos e a proliferação das imagens" (Perrot 1998: III). Este fenómeno será explicitado por Judith Butler, ao salientar que um dos aspectos fundamentais do feminino é funcionar como um "receptáculo permanente e por consequência uma coisa não viva e informe, que não pode ser nomeada. Enquanto ama, mãe, matriz do feminino, ele é assimilado a um conjunto de figuras" (Butler 2009: 66). Basta então atentar no nome de Isabel, a Rainha Santa idealizada, "encerrada na transparência das pedras" (Barreno/Horta/Costa 2010: 17), nas denominações de "Teresa de rosas" (idem: 8), referência à santa, ou, ainda, de Fátima, a virgem "da azinheira”, que se duplicam noutra genealogia, a das Três meninas outras três (idem: 131): Inês (a faca), Ofélia (a água), Joana (o lume) - uma última ramificação nominal que alude a uma outra imagem tradicional e histórica do feminino, a do feminino sacrificial, ilustrada por René Girard no conceito de "vítima emissária" (Girard 1972). Não é de espantar que as três autoras escolham começar a tarefa de libertação do ser feminino pelo reinvestimento/recitação de toda a onomástica feminina, que se relaciona com a única e frágil maneira de existir para as mulheres. 0 paradoxo feminino, assinalado pela questão dos nomes, reside no facto de que, como sublinha Butler, "ser nomead[a], é estar integrad[a] n[a lei simbólica] e constituir-se, como corpo, em conformidade com [esta lei]" (Butler 2009: 83). Afinal, a repetição dos nomes simula uma "citação da norma" e, ao mesmo tempo, problematiza esta norma para sair do impasse já apontado por Simone de Beauvoir, quando escrevia: 
La femme ne se connaît et se choisit non en tant qu'elle existe pour soi mais telle que l'homme la définit. Il nous faut donc la décrire telle que les hommes la rêvent puisque son être-pour-les-hommes est un des facteurs essentiels de sa condition. (Beauvoir 1976: 234)

Na continuação desta ideia, vários textos de Novas Cartas Portuguesas evocam claramente a confiscação do corpo da mulher pelo homem, chegando a uma forma de reificação/desmaterialização física pela violência. Carne para consumo e objecto do desejo masculino, a mulher torna-se uma boneca silenciosa, exilada de si mesma. ${ }^{9}$ Este movimento começa, por exemplo, em textos como O pai (Barreno/Horta/Costa 2010: 129) ou Texto sobre a solidão (idem: 191), que narram actos de violação ocorridos, quer numa relação incestuosa, quer numa situação matrimonial. No primeiro texto, a impressão de suavidade que se desprende da descrição das partes corporais da adolescente, reforçada pelos adjectivos "brando", "morno", "macio", "sedoso", é contrariada pela repetição abrupta de uma só frase: "é perversa". Assim, a visão da corporalidade adolescente, expressa através do ponto de vista masculino, é a de um corpo desmembrado e fragmentado. Com efeito, este resume-se "a braços, cabelos, pescoço, peitos, ombros, pernas e ventre", elementos que aludem ao corpo como matéria pronta a ser consumida, como uma carne ${ }^{10}$ ou um simples fruto, "cujo odor enlouquecido a entreabrir-se aos poucos, obsessivo: obsessivamente, obsessivamente" (idem: 130). Nesta situação, o acto de violação concretiza o consumo de um "corpo dócil" (Foucault 1975) à disposição do homem. Ora, na outra composição intitulada Texto sobre a solidão, a fruição do corpo feminino pelo companheiro ${ }^{11}$ provoca o alheamento pessoal e o desdobramento físico e psíquico da mulher, sintomáticos de uma crise identitária. Esta ideia é sublinhada pela repetição da frase "Mónica pensou: eu enlouqueço" (Barreno/Horta/Costa 2010: 192). De maneira geral, a situação vivida pelas personagens femininas tornar-se-á exemplar do que Monique Wittig (Wittig 2007) e Colette Guillaumin definem como o "sexage", em referência ao "servage" (servidão) ou "esclavage" (escravatura) aplicados à condição feminina. 0 "sexage" será "um direito de todos os homens (pai, esposo ou companheiro) a cada uma das mulheres" (Guillaumin 1992: 42). As implicações avassaladoras e aniquiladoras deste direito masculino inscrevem-se no texto 
no nome que a vítima de incesto repete para se nomear: "Claro que sou uma puta, podes estar tranquilo..." (Barreno/Horta/Costa 2010: 130).

Porém, o auge do processo de despersonalização feminina é atingido noutro texto intitulado 0 Cárcere (idem: 169). Aqui, a mulher passa da asfixia interior à decomposição pura e simples da sua integridade física. A presença e a violência física do homem reduzem a mulher ao estado de vulto fantasmático ou de corpo morto-vivo. Logo de início, o ser feminino é apenas perceptível, porque nem sequer é nomeado através da utilização de um pronome pessoal. Depois, num momento de violência insuportável, a mulher é metodicamente desmembrada e dilacerada, reduzida a um "existir só por aquele partir e esmagar" (idem: 170). Assim, a personagem feminina desprende-se do seu invólucro carnal, como o indicam as frases "seu corpo todo feito numa massa mole, desconhecida, só a si ligada pela dor" ou, ainda, "julgando-se no limite daquela decomposição interior" (ibidem). Estas frases exprimem um exílio e um estranhamento e, ao mesmo tempo, aludem a uma perda concreta de todos os contornos físicos, manifestada pelo apagamento de todas as fronteiras entre sensações internas e percepção externa do corpo. A personagem torna-se emblema de uma forma de desintegração do ser feminino, provocada por uma dissolução dos seus limites corporais. Assim, outra narradora acaba por constatar: "Tu, irmã, a da morte, a da carne, dizes, irmã, 'Só o corpo' e se nada podemos com ele que seja cadáver?” (idem: 287).

\section{“Mon corps m'appartient"12}

Porém, para além da tonalidade pessimista desta frase, a inclusão entre aspas da expressão "só o corpo", no meio da frase, soa como um apelo a todas as mulheres. Efectivamente, há em Novas Cartas Portuguesas a injunção a um regresso a este território perdido, para o redescobrir e o tornar todo seu. Um movimento que a poeta norte-americana Adrienne Rich definiu como "uma política da localização" e que consiste em "começar, assim, não por um continente, por um país ou por uma casa, mas pela geografia mais próxima - o corpo. (...) tentar ver, como mulher, a partir do centro" (Rich 2002: 1920). 
Efectivamente, na obra, o exercício de reconstrução identitária passa por um centramento da escrita no próprio corpo feminino, mergulhando no mundo das suas sensações e da sua sexualidade. Nos seus textos, as Três Marias dão corpo e voz às mulheres, fazem-nas passar "do silêncio ao grito" (Besse 2013: 1-9) e provam que as "Mulheres [podem] regressa[r] da sua hibernação sexual [e] (...) habit[ar] seu corpo".13 A partir daqui, assistimos a um contraponto relativamente à imagem da "mulher-eunuco" (Greer 1971), definida por Germaine Greer como o símbolo de um feminino cuja sexualidade foi negada e cujo corpo é representado como castrado e assexuado. Deste modo, vários textos falam de uma recusa da passividade, bem expressa na frase "Recusando sermos sombra, sedativo, repouso do guerreiro" (Barreno/Horta/Costa 2010: 32) e depois prolongada por uma afirmação maior: “(...) nós, mulheres de corpo inteiro e segura mão" (idem: 32). Nestas linhas emerge a mulher "senhora de si" (Horta 2015), ciente dos seus desejos e do seu valor. Esta "nova mulher" surge, num primeiro momento, em aberto diálogo com a freira Mariana. Com efeito, no texto Monólogo para mim a partir de Mariana seguido de uma pequena carta, a personagem é retrabalhada através do tema da sexualidade como via para o autoconhecimento e a autoconsciência:

Em tua cela às ocultas, conhecias o gosto dos braços e o suor dos corpos, a doçura das línguas, a dureza erecta de quem te visitava o ventre. Quantos homens Mariana assim te libertaram do convento? Uns te deixaram, a outros enganaste. Mas que outra maneira terias afinal de te afirmares? (Barreno/Horta/Costa 2010: 112)

Na personagem estabelece-se um paralelo entre a exploração táctil do corpo, ligada à actividade sexual, e o acto fundador de uma auto-afirmação. A posição do corpo de Mariana, nu e adormecido, faz coincidir sexualidade e afirmação de um ser, na medida em que o seu corpo se encontra numa "tão evidente posição de liberdade e vício" (ibidem). É de notar que, embora a palavra "vício" denote algo de negativo e transgressivo, a relação da personagem com o seu próprio corpo fica imediatamente "des-censurada". Assim, é a partir da variedade de sentidos e de sensações construída por Mariana através do seu corpo que uma outra cartografia do feminino se começa a desenhar. Nela, o corpo é, simultaneamente, 
o centro, a propriedade e o território para o uso pessoal da mulher. Um motivo de apropriação/exploração que se torna mais preciso, na Segunda Carta IV (idem: 67), quando se assiste a uma subversão do cânone da cena de amor. Logo de início, o texto adopta a perspectiva da personagem feminina e oferece a visão de uma presença física forte, evidenciada por um corpo feminino em movimento, como o indicam os verbos de acção: "volto-me", "viro-me", "conduzo" (idem: 68-9). A visão deste corpo, cujo rosto não é definido, é marcada por expressões lacónicas e fragmentárias como "seios, ancas macias, plana barriga, púbis", ou apenas por "pernas, longas, lisas, os pulsos". São elementos que, por um lado, rompem com os atributos ligados à feminilidade clássica e, por outro, manifestam a imagem de um corpo "simplificado", facilitando a captação de um "mero eu". Um "eu" que na interacção com o corpo masculino, se torna agente principal, matéria nua e viva. Será esta a impressão que se destaca de frases como "exercício de ti", ou "apenas os pulsos, tensos, dirigem o que tenho e te conduzo o pénis na lenta introdução em mim" (idem: 69-70). É através destes aspectos que alguns dos textos prefiguram "uma reivindicação/desconstrução [do corpo feminino] que se torna imprescindível para a construção de uma consciência da mulher, (...) isto vai fazer com que a mulher recupere este corpo 'confiscado', (...) para se atrever a sentir o prazer, o gozo, o tesão" (Sant'Ana 2006: 14).

\section{“On va leur montrer nos sextes"14}

Assim, o grande "manifesto" de Novas Cartas Portuguesas coincide com a origem do escândalo que as envolve, isto é, com a apropriação do "continente negro" de Freud, o lugar de todas as angústias masculinas, e a exploração explícita desta "innocent shell, holder of sound (...)" (Kristeva 1986: 173). É este o acto político, eminentemente transgressivo, reivindicado pelas autoras quando afirmam em uníssono ou individualmente, "Mitos desfloramos" (Barreno/Horta/Costa 2010: 70) ou “(...) sinto essa alegria (...) de se haver desaconchegado um mito, desflorado uma lei (...)" (idem: 38). Através da utilização do verbo "desflorar", as Três Marias anunciam que o reinvestimento do corpo pela mulher não se pode dar sem um regresso ao lugar inicial da sua opressão: o seu sexo. Efectivamente, num 
texto como Intimidade, a voz da narradora insiste na imagem tradicional da sexualidade feminina, ligada à conjugalidade, utilizando a sucessão de palavras, "A casa, a arca, a cama” (idem: 108) e prolongando-a na imagem reiterada da "colcha" ou "da colcha que a tua ama bordou”. Além disso, há uma pormenorização extrema da visão da colcha, valendo-se de descrições como "renda lilás não pendida"15, "a renda aberta, roxa".16 Estes elementos sublinham a tessitura, as pregas, o tecido e as cores, provocando uma alusão clara ao próprio "sexo feminino". Da "colcha" o texto desliza para a "concha". "A colcha" torna-se metonímia de uma parte do corpo feminino redescoberto por Mariana como território de prazer. Em suma, a colcha "Fendida, [transforma-se numa] bandeira que tu ostentas, mostrada porque é bonita, também porque afirma a liberdade aprendida que te magoa e defende" (idem: 110).

Nestas condições, quando os textos das Três Marias fazem do corpo matéria atingem um grande poder de sugestão para fixarem a imagem de um corpo feminino na sua mais crua intimidade. É essencialmente a partir destes elementos sugestivos que a própria escrita acaba por "[i]nvert[er], transgred[ir], e desconstru[ir] os papéis sexuais, rompendo com a ideia da ignorância do corpo" (Sant'Ana 2006: 22) pelo ser feminino e provocando o que Butler analisa como

(...) uma proliferação dos prazeres fora da economia reprodutiva [que] deixa vislumbrar uma forma especificamente feminina e difusa de erotismo, entendida como contra-estratégia face à construção reprodutiva da genitalidade (...). (Butler 2005: 99)

Assim, a partir do momento em que é possível às mulheres converterem o seu corpo num território todo seu, também será possível imaginar a substituição da "verticalidade fálica" pela noção de "profundidade útera" como elemento valorizado e criador. Esta ideia é expressa quando uma das vozes femininas ousa afirmar:

os homens sempre se teceram e sonharam no que é forma extrovertida, no que se erige, no que rasga o espaço. Por isso, dos poços e das profundezas nada sabem, nada nos sabem. (Barreno/Horta/Costa 2010: 39) 
Esta constatação corresponde a uma nova maneira de ser, ligada a um verdadeiro movimento de empoderamento no feminino, no qual, como afirma Annie Anzieu: "Un creux n'est ni un manque, ni un vide. (...) C'est une ouverture vers une profondeur délimité par l'enveloppe. Un lieu en soi, susceptible d'une activité propre et autonome" (Anzieu 2004: 42). Finalmente, este "empoderamento feminino" reflecte-se também numa forma de "histerização do espaço social" (Cixous 2010: 15), evidenciada por um erotismo no feminino ${ }^{17}$ como maneira de romper com o que Foucault qualificou de "sensualização do poder" (Foucault 1976: 61). ${ }^{18}$ É um dos temas desenvolvido pelo texto intitulado, A paz, quando Mariana Alcoforado rompe com a sua clausura corporal e transgride todos os tabus. ${ }^{19} \mathrm{Na}$ cena de masturbação, a personagem não só se "compraz (...) com o seu corpo, ensinada de si", chegando ao ponto de tornar seu ex-amante num "pretexto" e "memória" (Barreno/Horta/Costa 2010: 36-7), como também transforma o homem num puro objecto de gozo no "movimento ritmado das coxas, a possuí-lo como macho" (idem: 37). A afirmação da mulher pelo erotismo ou, melhor, pela harmonia auto-erótica, não só remete para um lema feminista do tipo "mon corps m’appartient", esboçado no final do texto pela expressão “(...) caso queira, com o corpo, Mariana se comprazer" (ibidem), como também é capaz de produzir um "corpo mutante" (Dorlin 2009: 61-9). Com efeito, este "corpo mutante" aparece, em particular, na celebração de um corpo feminino liberto das suas injunções sexuais, aberto aos seus desejos e, por isso, "não monarquizado" (Cixous 2010: 15). Ora, esta celebração constitui a matéria-prima de Novas Cartas Portuguesas, um acto fundador relacionado com o conceito de "escrita-mulher" (Didier 1981). Nestas condições, surgirá uma escrita-manifesto, projectada quando as correntes invisíveis da genealogia descontínua entre Mariana e Marias se materializam num corpo feminino reinventado pela escrita. Será esta: "Brando queixume que te escapa, me ocupa, me emprenha, me ultrapassa e mata: minha escrita" (Barreno/Horta/Costa 2010: 114).

É através do regresso puro e simples à materialidade do corpo que a obra das Três Marias abre o movimento de desconstrução e de remodelagem de um "novo corpo" feminino, multissensorial e plurifacetado. ${ }^{20}$ A inscrição e a fixação deste "corpo mutante" na escrita, quebram os interditos e abrem o caminho para o que Hélène Cixous anunciava no 
Riso da Medusa, em 1975. Mais precisamente, uma relação "des-censurada da mulher com a sua sexualidade, com o ser-mulher, devolvendo-lhe um acesso às suas próprias forças; aos seus bens, seus prazeres, seus órgãos e aos seus imensos territórios corporais 'confiscados' (...)" (Cixous 2010: 45). É este, ainda hoje, o legado mais precioso deixado às mulheres por um livro como Novas Cartas Portuguesas.

\section{NOTAS}

${ }^{1}$ Expressão utilizada por François Mauriac numa carta datada de 1950 a um dos colaboradores da revista Les Temps Modernes: "J'apprends beaucoup de choses sur le vagin et le clitoris de votre patronne" (apud Galster 2004: 14-5).

2 “Les faits et les mythes” é precisamente o subtítulo do livro Le Deuxième Sexe de Simone de Beauvoir.

${ }^{3}$ Referimo-nos ao depoimento de Maria Lamas em defesa das 3 Marias no Tribunal da Boa-Hora, no dia 1 de Março de 1974. Lamas declarara que o livro se referia à sujeição das mulheres, à sua vida íntima (sexual), e que era, por isso, um "livro de choque" (Vidal 1974).

4 Paula C. Ribeiro da Rocha de Morais Cunha escreve que “(...) falar do corpo e do desejo feminino, das ânsias, aspirações e sentimentos da mulher, equivale a partir à descoberta da sua identidade, à exploração de si própria" (Cunha 2012: 6).

${ }^{5}$ Retomamos o famoso título inglês “Bodies that matter”, de Judith Butler (Butler 2009).

${ }^{6}$ Retomamos aqui uma parte da frase da Segunda Carta II: "Maria é a raiz, e o exercício de Maria seria a contaminação pela suspeita, trabalho quieto e de sapa, até que em todo o pão e em todas as laranjas pesasse a suspeita de estarem envenenadas" (Barreno/Horta/Costa 2010: 25).

7 Mariana Alcoforado, freira das primeiras Lettres Portugaises, publicadas em francês no ano de 1669 pelo editor Claude Barbin em Paris.

N. 35 - 12/ 2016 | 279-294 - ISSN 1645-1112 | http:/dx.doi.org/10.21747/16451112/litcomp35a14

INSTITUTO DE LITERATURA COMPARADA MARGARIDA LOSA I WWW.ILCML.COM 
${ }^{8}$ Reparemos como os nomes de Maria, Isabel, Inês e Fátima remetem desde já para arquétipos femininos enaltecidos pelo salazarismo e valorizados como modelo para a mulher portuguesa.

${ }^{9}$ Em Novas Cartas Portuguesas, esta forma de reificação/desmaterialização começa por ser problematizada através do tema do "amor", visto como uma "ficção" ou uma construção masculina. Relembremos a este propósito o trabalho do historiador George Duby sobre o amor ou o modelo cortês (Duby et al. 1990: 323-42). Em Novas Cartas Portuguesas, existe justamente a denúncia do "amor" (diferente da noção de "paixão" desenvolvida nos textos), que começa com um desabafo de Mariana - "e o amor? (...) Porque os inventaram, se tudo é trato manso e mulher honrada" - e acaba numa constatação de impotência feita pela narradora: “(...) não Mariana nem isto gritou: apenas disse 'aqui estou eu, possuída pelo amor"' (Barreno/Horta/Costa 2010: 141).

${ }^{10}$ Ver a este propósito a tese de mestrado de Marta M. Pessanha Mascarenhas Simosas (2007: 90).

${ }^{11}$ Neste texto, um dos processos mais reveladores da fruição do "corpo dócil" feminino reside no contraste entre a expressão "És bela", repetida várias vezes pelo companheiro, e um acto concreto de violação "legitimado" pelo matrimónio: "Gosto que tenhas nojo mas que venhas comigo para a cama" (Barreno/Horta/Costa 2010: 191).

${ }^{12}$ Esta frase é um dos lemas do movimento feminista da segunda fase em França, culminando essencialmente no contexto de Maio de 1968.

${ }^{13}$ Parafraseamos e subvertemos aqui uma das frases de Novas Cartas Portuguesas: “(...) as mulheres regressam da sua longa da sua hibernação sexual mas ainda não habitam seu corpo, olham-no, falam dele como dum animal de muita estimação" (Barreno/Horta/Costa 2010: 284).

${ }^{14}$ Citamos aqui um excerto da frase "Qu'ils tremblent, les prêtres, on va leur montrer nos sextes" (Cixous 2010: 54).

15 "Tua ou minha colcha antiga se bem que de imitação, renda lilás não pendida, franja no chão, sobre a madeira (...). De baços dias se estende, o seu brando pano verde velho, tecido de leite e vinho e outras maneiras dela" (Barreno/Horta/Costa 2010: 109-10).

16 "Tuas unhas rasgando tua pele, a colcha, o lençol de linho onde te encontras: o chão, a pedra e novamente a colcha, (...) a renda aberta, roxa, o pano verde, no tom macio onde te esvais agora (...)" (Barreno/Horta/Costa 2010: 108).

${ }^{17}$ Maria Graciete Besse escreve a este respeito que as Três Marias que "(...) en touchant à un domaine traditionnellement réservé aux hommes: la littérature Érotique. Elles s'éloignent par conséquent de l'image 'fleur bleue' qu'impose le mythe de la féminité et échappent à l'emprise des codes de moralité - tout 
naturellement, leur livre est accusé de pornographie par le régime conservateur et très catholique" (Besse 2006: 72).

${ }^{18}$ Michel Foucault sublinha que "[l]e pouvoir qui, ainsi, prend en charge la sexualité, se met en devoir de frôler les corps, il les caresse des yeux; il en intensifie des régions; il électrise des surfaces (...). Il prend à bras-le corps le corps sexuel. Accroissement des efficacités sans doute et extension du domaine contrôlé. Mais aussi sensualisation du pouvoir et bénéfice du plaisir" (Foucault 1976: 61).

${ }^{19}$ Este movimento é anunciado, por exemplo, na pergunta fatídica: "E o erotismo? Senhores, e o erotismo? Em quase todos os livros 'il n'y a pas des femmes libres, il y a des femmes livrées aux hommes...." (Barreno/Horta/Costa 2010: 205).

${ }^{20}$ Ver a este propósito o artigo de Ana Luísa Amaral, "Desconstruindo identidades: Ler as Novas Cartas Portuguesas à luz da teoria Queer" (Amaral 2001: 2-3). 


\section{Bibliografia}

Alcoforado, Mariana (1993), “Lettres Portugaises”, Cartas Portuguesas, Lisboa, Assírio e Alvim [1669].

Amaral, Ana Luísa (2001), "Desconstruindo identidades: Ler Novas Cartas Portuguesas à luz da teoria Queer", Cadernos de Literatura Comparada, no 3/4, Porto. Consulta do 16 de Outubro de 2013: https://repositorio-aberto.up.pt/bitstream/10216/23339/2/ analuisaamaraldesconstruindo000094787.pdf

Anzieu, Annie (2004), La femme sans qualité, Paris, Ed. Dunod.

Barreno, Maria Isabel/Maria Teresa Horta/Maria Velho da Costa (2010), As Novas Cartas Portuguesas, Edição Anotada. Org. Ana Luísa Amaral, Lisboa, Publicações Dom Quixote [1972].

Beauvoir, Simone de (1976), Le deuxième sexe, Vol. I e II, Paris, Editions Gallimard [1949].

Besse, Maria Graciete (2006), La littérature portugaise, Aix-en-Provence, Edisud.

-- (n/d), "Entre le cri et le silence: la voix des femmes dans la littérature portugaise contemporaine", Paris, CRIMIC, 1-9. Consulta a 11 de Outubro de 2013: http://www.crimic.paris-sorbonne.fr/IMG/pdf/besse.pdf

Butler, Judith (2005), Trouble dans le genre. Pour un féminisme de la subversion, Paris, Editions La découverte [1990].

-- (2009), Ces corps que comptent. De la matérialité et des limites discursives du «sexes», Paris, Editions Amsterdam [1992].

Cixous, Helène (2010), Le rire de la Méduse et autres ironies, Prefácio de Frédéric Regard, Paris, Editions Galilée [1975].

Cunha, Paula Cristina Ribeiro da Rocha de Morais (2012), “Da crítica feminista e a escrita 
feminina", in Revista Criação e Escrita, São Paulo, 6. Consulta a 10 de Novembro de 2013: http://revistas.usp.br/criacaoecritica/article/view/46837

Didier, Béatrice (1981), L'écriture-femme, Paris, PUF/Ecriture.

Dorlin, Elsa (2009), La matrice de la race, Paris, La Découverte.

-- (2008), Sexe, genre et sexualités. Introduction à la théorie féministe, Paris, PUF.

Duby, George et al. (1990), Histoire des femmes. Vol. II. Le Moyen Age, Paris, Editions Perrin.

Foucault, Michel (1975), Surveiller et punir. Naissance de la prison, Paris, Gallimard.

-- (1976), Histoire de la sexualité I, La volonté de savoir, Paris, Gallimard.

Galster, Ingrid (2004), Le deuxième sexe de Simone de Beauvoir, Paris, Presses de l'Université de Paris Sorbonne.

Girard, René (1972), La violence et le sacré, Paris, Hachette Littératures.

Greer, Germaine (1971), La femme Eunuque, Paris, Ed. Robert Lafont.

Guillaumin, Collette (1992), Sexe, Race et pratique du pouvoir, Paris, Côté Femmes.

Horta, Maria Teresa da (2015), Minha senhora de mim, Lisboa, Publicações Dom Quixote.

Kristeva, Julia (1986), "Stabat mater", in Kristeva's Reader, Ed. Toril Moi, New York, Columbia University Press.

Machado, José Pais (1996), "Austeridade e moralismo nos valores estéticos", in Portugal Contemporâneo, Dir. António Reis, Lisboa, Publicações Alfa, 349-352.

Perrot, Michelle (1998), Les Femmes ou les silences de l'Histoire, Paris, Flammarion.

Rich, Adrienne (2002), "Notas para uma política da localização", in Genero, identidade e desejo: antologia crítica do feminismo contemporâneo, Org. Ana Grabriela Macedo, Lisboa, Cotovia, 15-35.

Sant'Ana, Mónica (2006), “A escrita feminina e as suas implicações: a ocorrência ao corpo como signo de identidade", REEL: Revista Electrônica de Estudos Literários, Vitória, a. 2, n. ${ }^{\circ}$ 2, 1-26. 
Simosas, Maria Marta Pessanha Mascarenhas (2007), A Fluida Arte da Descosura. Filosofias de liberdade em Cartas Portuguesas e Novas Cartas Portuguesas, Mestrado em Literatura e Cultura Comparadas, Faculdade de Letras da Universidade do Porto. Consulta a 10 de Novembro de 2013: http://web.letras.up.pt/ilc/fluida.pdf

Vidal, Duarte (1974), O Processo das Três Marias, Editorial Futura Panfleto, Lisboa.

Vigarello, Georges (2004), Histoire de la beauté, Paris, Editions du Seuil.

Wittig, Monique (2007), La pensée Straight, Paris, Editions Amsterdam.

\begin{abstract}
Alda Maria Lentina é Professora Auxiliar na Universidade de Dalarna, Suécia. É doutorada pela Universidade de Paris-Sorbonne - Paris IV, com uma tese intitulada Agustina BessaLuís et l'écriture de l'Histoire (2012), para a qual beneficiou de uma bolsa da Fundação para a Ciência e a Tecnologia. É membro permanente do Centro de Pesquisas Kultur, identitet och gestaltning (KIG) - Grupo Litteratur, Identitet och Transkulturalitet (LIT) na Universidade de Dalarna e do Centre de Recherches Interdisciplinaires sur les Mondes Ibériques (CRIMIC) na Universidade de Paris-Sorbonne, Paris IV. As suas áreas actuais de pesquisa são: Literatura dos países lusófonos, História das mulheres, Imagens e Representações do feminino e do masculino, "Ecriture-femme", Alteridade, Pós-modernidade, Identidade nacional e Desconstrução, "Gender Studies" e "Postcolonial studies".
\end{abstract}


As Novas Cartas Portuguesas ou uma nova cartografia do feminino

N. 35 - 12/ 2016 | 279-294 - ISSN 1645-1112 | http:/dx.doi.org/10.21747/16451112/litcomp35a14 